\title{
Mindfulness, relationship quality, and conflict resolution strategies used by partners in close relationships
}

\author{
Eugenia Mandal (1D) ${ }^{A, C, D, E, F}$, Martyna Lip (D) $^{A, B, C, D, E, F}$ \\ Institute of Psychology, University of Silesia, Katowice, Poland
}

\section{BACKGROUND}

Mindfulness is a specific state of attention which involves a constant focus on what is happening at the present time in a way that is neither judgmental nor evaluative. The aim of this study was to investigate the importance of mindfulness for relationship quality and conflict resolution strategies in close relationships. Five components of mindfulness were examined: observing, describing, acting with awareness, nonjudging, and nonreactivity.

\section{PARTICIPANTS AND PROCEDURE}

The study included 153 participants (79 women, 74 men; aged $19-60$ years). $39.2 \%$ of the respondents were married, $20.9 \%$ were engaged, 39.9 were in romantic relationships. The mean duration of the close relationship was 6.25 years. The following measures were used: the Five Facet Mindfulness Questionnaire, the Patterns of Problem Solving Questionnaire, and the Dyadic Adaptation Scale.

\section{RESULTS}

Acting with awareness, dialogue and avoiding conflict escalation strategy were predictors of relationship quality.
The relationship status (marriage and engagement) was also a predictor of relationship quality. Gender, age, and duration of the relationship were not predictors of relationship quality. The results showed correlation between mindfulness and relationship quality $(r=.28)$. There was a positive correlation between nonjudging and satisfaction in the relationship and between describing and emotional expression. Also, there was a negative correlation between nonreactivity and compatibility. Mindfulness was positively correlated with dialogue and negatively correlated with escalation of and withdrawal from a conflict.

\section{CONCLUSIONS}

Mindfulness is important to the relationship's quality and conflict resolution strategies. Among the components of mindfulness, especially acting with awareness is important to relationship quality.

\section{KEY WORDS}

mindfulness; marital satisfaction; relationship quality; conflict resolution strategies

CORReSPONDing AUthor - Prof. Eugenia Mandal, Institute of Psychology, University of Silesia, 53 Grażyńskiego Str., 40-126 Katowice, Poland, e-mail: eugenia.mandal@us.edu.pl

AUthors' CONTRIBUtion - A: Study design - B: Data collection - C: Statistical analysis - D: Data interpretation .

E: Manuscript preparation · F: Literature search · G: Funds collection

to Cite this ARTICLE - Mandal, E., \& Lip, M. (2022). Mindfulness, relationship quality, and conflict resolution strategies

used by partners in close relationships. Current Issues in Personality Psychology, 10(2), 135-146.

RECEIVED 18.01.2021 · REVIEWED 30.03.2021 · ACCEPTED 22.11.2021 · PUBLISHED 24.01.2022 


\section{BACKGROUND}

\section{MINDFULNESS}

Mindfulness is described as "the presence of mind", as a state of "pure consciousness" (Gunaratana, 2002; Shapiro et al., 2006). It can be understood as a result of the constant focus on what is happening at the present time, which is non-judgmental (Kabat-Zinn, 1990, 1994, 2003). It is the ability to find details from the peripheral perception field more easily, as well as to notice them preverbally and to keep them in the memory (Langer, 1989; Lazar, 2005). The term can be understood as open awareness that is directed at the individual's current experience (Brown \& Ryan, 2003; Pepping \& Duvenage, 2016). People who have a higher level of mindfulness can see details that are ignored by other individuals (Tredway \& Lazar, 2009). The concept of mindfulness is understood as a specific state, a technique, and a quality of life feature. It may be derived either from an individual's predisposition or from the use of mindfulness training (Didonna, 2009).

It has been proven that there is a positive impact of mindfulness on the individual's functioning. The positive relationship between mindfulness and reflectiveness was demonstrated with the reduction of nonadaptive forms of thinking (ruminations and worries) (Brown \& Ryan, 2003). Mindfulness also positively correlates with emotional and motivational aspects of life, i.e. with adaptive regulation of emotions, the needs of autonomy, competence, psychological wellbeing, empathy, self-compassion, resilience, sexual satisfaction and mental health (Baer et al., 2012; Bloch et al., 2017; Brown \& Ryan, 2003; Creswell \& Lindsay, 2014; Davidson, 2010; Dekeyser et al., 2008; Keng et al., 2011; Pepping et al., 2018; Rizal et al., 2020).

A greater tendency for mindful observation was associated with more engagement in empathy, with altruism, better identification and description of feelings, more body satisfaction, less social anxiety, and less distress contagion (Dekeyser et al., 2008; Ilies et al., 2019). There is a relationship between mindfulness and the level of self-esteem and authenticity (Brown \& Ryan, 2003). In addition, there has been a positive link between a high level of mindfulness and an increased level of daily enjoyment, an increased sense of autonomy, optimism, closeness, and acceptance of one another (Carson et al., 2004). Mindful attention can contribute to becoming aware of one's own thoughts and experiences, making it possible to observe them as current and passing mental events (Papies et al., 2015).

There is extensive literature on the relationship of mindfulness with health and well-being of the subject, while relatively few studies focus on the role of mindfulness in functioning in romantic relationships (Barnes et al., 2007; Burpee \& Langer, 2005; Carson et al., 2004; Jones et al., 2011). The aim of the study was to investigate the relationship between mindfulness, relationship quality, and conflict resolution strategies used by partners in romantic relationships.

\section{MINDFULNESS AND CLOSE RELATIONSHIPS}

Mindfulness can be important in close relationships. A relationship was reported between marital attachment, mindfulness and marital satisfaction (Burpee \& Langer, 2005; Jones et al., 2011). Carson et al. (2004) found that mindfulness had a positive effect on the daily joy of the relationship and the acceptance of and closeness to the partner.

Mindfulness was associated with partner acceptance (Kappen et al., 2018), sexual satisfaction (Pepping et al., 2018) and the mood in romantic relationships. A particularly high level of improvement and strengthening of the close relationship with the implementation of mindfulness training and an increase in the level of attentiveness were noted in couples who showed a high level of happiness (Sagrestano et al., 1999). It was noted that mindfulness in men was linked with higher levels of feeling loved and feeling supported, and mindfulness in women was associated with lower levels of relationship anxiety and relationship sadness (Iida \& Shapiro, 2017).

Bodenmann et al. (2001) showed that programs for couples that take into account the effects of mindfulness-care techniques improved their ability to cope with stressful situations. Barnes et al. (2007) found that trait mindfulness predicted greater capacity to respond constructively to relationship stress. It was also shown that problem-solving skills (Markman et al., 1988) and constructive conflict resolution strategies were positively associated with partner satisfaction, while destructive strategies were negatively associated with it (Barnes et al., 2007; Margolin \& Wampold, 1981; Rusbult et al., 1986).

Relationship quality is a complex concept that encompasses different subjective feelings, i.e. a sense of happiness, satisfaction, adaptation and communication. It depends on factors such as commitment, the ability to cope with difficult situations, respect for other alternatives, and religious beliefs. The partners' analysis of the quality of the relationship is possible on the basis of the profit and loss balance sheet (Spanier \& Lewis, 1980).

Spanier and Lewis (1980) distinguished the components of the quality of the close relationship that determine its success: (1) the couple's views on how the relationship is supposed to work, (2) cohesion, i.e. engaging in family life, (3) emotional expression, i.e. expressing oneself, one's emotions and showing one's attachment to another person in the relationship, and (4) satisfaction, connected with the need to be in the relationship and the desire to maintain it as long as possible. 
Communication about the emotions experienced, empathy and exchange of information between partners in a close relationship are the basis for the sense of cohesion and unity of the relation (Kaźmierczak, 2008; Mandal, 2008). Some misunderstandings, lack of cohesion and conflicts are natural elements of communication (Wilmot \& Hocker, 2011). Conflict is a concept that characterizes differences in goals, attitudes and tactics for dealing with situations in a close relationship (Korner et al., 1980).

The ability to identify a problem, exchange opinions, seek a solution, find a solution and compromise are important aspects of the feeling of satisfaction with a close relationship in a behavioral context (Jacobson \& Margolin, 1979). As time goes by and as partners get to know each other, they learn to express positive and negative emotions to each other. However, it was found that speaking openly about negative emotions or behaviors was not conducive to further good understanding of partners (Margolin \& Wampold, 1981; Noller, 1987).

There are two dimensions of the response to a romantic conflict: constructiveness-destructiveness, and activity-passivity (Rusbult et al., 1986). On the basis of these dimensions, four conflict resolution strategies can be distinguished:

(1) Dialogue (which is both an active and constructive strategy, while maintaining a close relationship at a level that satisfies both partners, and resolving conflict by discussing the problem). Partners who use dialogue as a form of conflict resolution ensure proper communication between themselves, and particularly value mutual openness and consideration of every possibility that is intended to alleviate tension in their relationship.

(2) Loyalty (which is a constructive and passive strategy) is mainly related to the lack of action to resolve the conflict, waiting for the problem to resolve itself. Partners want to wait the problem out, trusting that it will be forgotten, and everything will return to normal.

(3) The escalation of conflict, which is an active but destructive strategy, manifests itself in negative behavior towards the partner. Such behaviors may include accusation, criticism or verbal aggression. At the same time, the partner exerts a strong negative influence and expresses their negative emotions without restraint.

(4) Withdrawal, which is a passive and destructive strategy, manifests itself in a lack of commitment to the partner relationship. It consists in ignoring the other person and reducing the amount of time he/she previously spent with him/her. Partners who apply this strategy more often refuse to enter into a dialogue or discussion and treat each other coldly.

Destructive problem-solving responses were more powerfully predictive of couple distress/nondistress than constructive problem-solving behaviors (Rus- bult et al., 1986). Couples who are dissatisfied with their relationship are more likely to criticize their partner, which can result in increased tension in the relationship. The growing misunderstandings and accumulating tensions are destructive to close relationships. Couples were more likely to divorce when partners reported higher marital tension (i.e. feelings of tension, resentment, irritation) (Birditt et al., 2017). In marital conflicts, men prefer coercive behavior rather than reconciliation. Women tend to exert pressure on matters of importance to them, which men most often respond to by avoidance (Markman, 1991; Markman et al., 1988, 1994).

\section{MINDFULNESS AND GENDER}

Studies on gender differences in mindfulness have not been conducted yet. In the context of gender differences, it can be assumed that mindfulness is a characteristic associated with emotionality, rationality, and empathy as the ability to empathize with emotions and understand other people.

Research on empathy between women and men has shown that gender differences depend on measurement methods and the situational context. Analyses have demonstrated that there is a large sex difference favoring women when the measure of empathy was assessed using self-report scales. Moderate differences (favoring females) were found for reflexive crying and self-report measures in laboratory situations. No sex differences were evident when the measure of empathy was physiological or unobtrusive observations of nonverbal reactions to another's emotional state (Eagly \& Crowley, 1986; Eisenberg \& Lennon, 1983).

There are also cognitive empathy (mental perspective taking) and emotional empathy (the vicarious sharing of emotion) (Smith, 2006). At the same time, numerous analyses have emphasized that the differences between the sexes related to rationality (greater in men) and emotionality (greater in women) of sex were related to different biological and social roles of women and men (Eagly et al., 2000; Eagly \& Koenig, 2006; Fischer, 2000; Mandal, 2003). It may be argued that possible gender differences in mindfulness of women and men may have an important impact on functioning in close relationships, including the influence on conflict resolution strategies and the quality of a relationship.

\section{THE PRESENT STUDY}

The aim of the present study was to investigate the relationship between mindfulness, relationship quality, and the conflict resolution strategies used by partners. Based on the fundamental assumptions about 
mindfulness indicating its positive impact on the well-being of the individual, the current study investigated the relation between mindfulness and a sense of quality in close relationships. It was hypothesized that there was a positive correlation between mindfulness and relationship quality in close relations.

The study also investigated the relationship between mindfulness and preferred conflict resolution strategies used by partners in close relationships. It was hypothesized that mindfulness positively correlated with the tendency to use constructive strategies (dialogue, loyalty) and negatively with destructive strategies (conflict escalation, withdrawal).

A secondary goal of the study was to compare mindfulness of men and women. In the context of knowledge about similarities and differences between the sexes in terms of emotional empathy and rational empathy, the study hypothesized that women and men did not differ significantly in terms of mindfulness. It was also assumed that both sexes had a similar level of satisfaction with close relationships. On the other hand, based on the knowledge that women are more likely to react emotionally than rationally in marital conflict situations, it was assumed that women would be more likely to use the conflict escalation strategy compared to men.

\section{PARTICIPANTS AND PROCEDURE}

\section{PARTICIPANTS}

The research was conducted on a snowball sample in the recruitment process. The respondents were students of universities in Upper Silesia in Poland as well as their friends and family members. All respondents were of Polish nationality. 153 people (79 women and 74 men $)$ aged 19-60 $(M=27.71, S D=7.52)$ participated in the study.

The study assumed that close relationships were as follows: marriage, engagement, and romantic relationships. Participants were asked to answer whether they were currently in a close relationship. When the answer was positive, they were asked if they were in a relationship and about the form and duration of the close relationship. $39.2 \%$ of the respondents were married, $20.9 \%$ were engaged, $39.9 \%$ were in romantic relationships. The duration of the close relationship was $M=75$ months (6.25 years), $S D=78.66$ months (6.55 years) (range: 1 month to 38 years). $62.7 \%$ of the respondents lived with a partner, $29.4 \%$ lived separately, and $7.8 \%$ lived with a partner from time to time. $58.1 \%$ of the respondents had higher education, $36.6 \%$ had secondary education, and $5.3 \%$ had vocational education. $43.8 \%$ of the respondents lived in towns of up to 100,000 inhabitants, $42.3 \%$ in cities of between 100,000 and 300,000 inhabitants, and 13.9\% in cities of over 300,000 inhabitants.

\section{DATA COLLECTION}

The data were collected via the Internet. The respondents were provided with written instructions concerning the purpose of the research, its confidentiality, anonymity and voluntariness. Having provided informed consent, each participant completed a set of questionnaires in a random order. The respondents did not receive any gratification for participating in the study.

\section{RESEARCH MEASURES}

The following measures were administered:

The Five Facet Mindfulness Questionnaire (FFMQ; Baer et al., 2006; Polish adaptation: Radoń, 2014). This tool tests the general level of mindfulness. It also tests 5 subscales (dimensions) of mindfulness: Observing, Describing, Acting with awareness, Nonjudging of inner experiences, and Nonreactivity to inner experiences. The questionnaire consists of 39 statements, with possible answers concerning the frequency of behavior on a 5-point scale from 1 - (almost) never to 5 - (almost) always. There are 8 items in each subscale, and 7 items in the Nonreactivity subscale only. The results calculated according to the questionnaire key allowed the intensity of a given dimension to be determined - the higher the score on a given scale, the greater its intensity. The reliability coefficients of Cronbach's $\alpha$ for each scale of the questionnaire were: Nonreactivity - .66, Observing - .73, Acting with awareness -.79 , Nonjudging - .86, and Describing - .74. Examples of the questionnaire items belonging to different subscales were: Nonreactivity - "I am not forced to react to the emotions I feel"; Observing - "When I walk, I pay attention to the impressions coming from my moving body"; Acting with awareness - "I have difficulty concentrating on what is happening here and now"; Describing - "I can easily find the words to describe my feelings"; Nonjudging - "Assess whether my thoughts are right or wrong".

The Patterns of Problem Solving Questionnaire (Rusbult et al., 1986; Polish adaptation: Kriegelewicz, 2003). The questionnaire consists of 32 statements that refer to 4 conflict resolution strategies that describe reactions to dissatisfaction in a close relationship, i.e. dialogue (a constructive and active strategy), conflict escalation (a destructive and active strategy), loyalty (a constructive and passive strategy), and withdrawal (a destructive and passive strategy). The person is to mark the answer on a 6-point scale from 0 (never behaves in a given way) to 5 (always behaves in a given way). The score for each scale is $0-40$ points and the higher the score on a given scale, the greater the intensity of a given strategy being used as a means of resolving a conflict in a close relationship by an individual. The Cronbach's $\alpha$ reliability coeffi- 
cients for each scale were as follows: Dialogue -.89 , Escalation of conflict -.86 , Withdrawal -.91 , and Loyalty - .78.

The following are examples of questionnaire items belonging to particular scales: Loyalty - "If my partner makes me upset, I try to justify his/her behavior"; Escalation of conflict - "In anger, I sometimes say or do something I know will hurt my partner"; Dialogue - "When I feel sorry for my partner about something, I try to tell him/her calmly about what lies in my heart"; Withdrawal - "When my partner's behavior makes me angry, I stop talking to him/her".

The Dyadic Adjustment Scale (DAS; Spanier, 1976; Polish adaptation: Cieślak, 1989) distinguishes 4 main aspects of marital adaptation, i.e. cohesion, compliance, satisfaction, and emotional expression. The scale consists of 32 statements. The person is supposed to respond to each of them by determining the frequency or compliance with a given statement on 6- and 5-degree scales (always/never frequency scale). The subscale regions were distinguished: Compatibility (understood as the level of mutual agreement between spouses on matters that are relevant to the functioning of the relationship; for instance: family budget regulation; the possible number of points to receive in this case is 65); Satisfaction (the general feeling of satisfaction with the relationship is related to the need to be and remain in the relationship, for instance: "Do you trust your spouse?"; the person can score a maximum of 50 points in this subscale); Coherence (understood as the involvement of spouses in everyday life; for instance: "Are you involved in family responsibilities together?"; a maximum of 24 points); Emotional expression (refers to showing affection for each other; an example of the statement by means of which the subject is supposed to describe his/her relationship is: "Aversion to sexual intercourse due to excessive fatigue"; the possible score for this scale is 12). The number of points to score for the whole questionnaire is 151, according to the answer key.

The higher the score achieved in this subscale, the greater is the intensity of the aspect in a close relationship. Cronbach's $\alpha$ reliability coefficients were .96 for the DAS questionnaire, and for each subscale of the questionnaire were as follows: .90 (compliance), .94 (satisfaction), .86 (consistency), and .73 (emotional expression).

\section{RESULTS}

\section{STATISTICAL ANALYSES}

The results for the study group were measured and comparisons were made between the groups of women and men. The results showed that in the Five Facet Mindfulness Questionnaire (FFMQ), the overall level of mindfulness was $M=131.79(S D=15.36)$ for the whole study group; in the male group $-M=131.29$ $(S D=16.11)$ and in the female group $-M=132.25$ $(S D=14.71)$. Gender differences in overall mindfulness score and its dimensions were not statistically significant (Table 1).

In DAS, the average global relationship quality for the whole study group was $M=120.25(S D=14.91)$ (men $-M=119.74, S D=14.21$; women $-M=120.73$, $S D=15.62)$. Gender differences in the overall score and its dimensions were not statistically significant (Table 1).

The results in the Patterns of Problem Solving Questionnaire (SRK) showed that the respondents most often pointed to dialogue, followed by loyalty, withdrawal, and least often to the escalation of conflicts. Men $(M=23.74)$ stated that they used the strategy of loyalty statistically significantly more often than women $(M=21.5, p=.006)$, while women $(M=14.69)$ admitted to using escalation of conflicts more often than men $(M=12.58, p=.041)$ (Table 1$)$.

Next, an analysis of the correlation between all studied variables was performed. The results showed statistically significant, small correlations between mindfulness in general (FFMQ total score) and relationship quality in general (DAS total score) $(r=.28$, $p=.006)$. There were small correlations between mindfulness and the components of relationship quality: satisfaction $(r=.27, p=.001)$, and cohesion $(r=.26, p=.001)$. Compatibility was statistically insignificant $(r=.15, p=.064)$.

Also, a statistically significant, medium correlation was found between nonjudging and satisfaction in relationship $(r=.31, p<.001)$. A small correlation was found between desrcibing and emotional expression $(r=.25, p=.002)$. A small negative correlation was found between nonreactivity and compatibility $(r=-.26, p=.001)$ (Table 2).

There are statistically significant, medium correlations between mindfulness and conflict resolution strategies. Mindfulness was positively correlated with dialogue $(r=.31, p<.001)$ and negatively correlated with conflict escalation $(r=-.44, p<.001)$ and withdrawal $(r=-.41, p<.001)$ (Table 2$)$.

There were statistically significant correlations between relational quality and conflict resolution strategies. A large correlation was noted between relationship quality and dialogue strategy $(r=.51$, $p<.001)$. Also, a medium correlation was observed between relationship quality and loyalty as a conflict resolution strategy $(r=.32, p<.001)$. There was also a negative correlation between the quality of the relationship and the withdrawal strategy $(r=-.36$, $p<.001)$. A negative correlation was also found between the quality of the relationship and the escalation of the conflict $(r=-.35, p<.001)$ (Table 2).

The study showed that there were statistically significant large and medium correlations between satisfaction and conflict resolution strategies. Dia- 
Mindfulness and relationship quality

Table 1

Mindfulness, relationship quality, and strategies of problem resolving in study groups of women and men

\begin{tabular}{|c|c|c|c|c|c|c|c|c|}
\hline \multirow[t]{2}{*}{ Variable } & \multicolumn{2}{|c|}{ Women } & \multicolumn{2}{|c|}{ Men } & \multicolumn{2}{|c|}{ Total } & \multirow[t]{2}{*}{$t$} & \multirow[t]{2}{*}{$p$} \\
\hline & M & $S D$ & $M$ & $S D$ & $M$ & $S D$ & & \\
\hline Mindfulness (general) & 132.25 & 14.71 & 131.29 & 16.11 & 131.79 & 15.36 & 0.38 & .702 \\
\hline Nonjudging & 28.20 & 6.11 & 28.19 & 6.69 & 28.19 & 6.38 & -0.21 & .834 \\
\hline Describing & 29.16 & 5.26 & 28.64 & 5.91 & 28.91 & 5.58 & 0.78 & .438 \\
\hline Acting with awareness & 29.15 & 4.68 & 29.12 & 6.03 & 29.14 & 5.36 & 0.03 & .972 \\
\hline Observing & 25.49 & 5.62 & 24.27 & 6.59 & 24.90 & 6.12 & 1.24 & .218 \\
\hline Nonreactivity & 20.24 & 3.73 & 21.08 & 5.04 & 20.65 & 4.42 & -1.17 & .241 \\
\hline Relationship quality (general) & 120.73 & 15.62 & 119.74 & 14.21 & 120.25 & 14.91 & 0.64 & .523 \\
\hline Compatibility & 52.49 & 7.09 & 51.49 & 8.20 & 52.01 & 7.64 & 0.79 & .424 \\
\hline Satisfaction & 40.52 & 5.57 & 40.55 & 5.32 & 40.54 & 5.44 & 0.16 & .877 \\
\hline Cohesion & 17.59 & 3.63 & 17.84 & 2.89 & 17.71 & 3.28 & -0.13 & .897 \\
\hline Emotional expression & 10.13 & 1.77 & 9.86 & 2.17 & 10.00 & 1.97 & 0.41 & .684 \\
\hline \multicolumn{9}{|l|}{ Patterns of problem resolution } \\
\hline Dialogue & 29.54 & 7.05 & 27.74 & 8.82 & 28.67 & 7.98 & 1.00 & .321 \\
\hline Loyalty & 21.59 & 5.52 & 23.74 & 6.30 & 22.63 & 5.99 & -2.74 & .006 \\
\hline Escalation of conflict & 14.69 & 7.44 & 12.58 & 7.90 & 13.67 & 7.72 & 2.01 & .041 \\
\hline Withdrawal & 16.45 & 6.53 & 15.02 & 6.42 & 15.76 & 6.50 & 1.16 & .242 \\
\hline
\end{tabular}

logue $(r=.50, p<.001)$ and loyalty $(r=.31, p<.001)$ were positively correlated with satisfaction from a close relationship, but conflict escalation $(r=-.44$, $p<.001)$ and withdrawal $(r=-.42, p<.001)$ were negatively correlated.

Next, linear regression analysis for relationship quality (DAS overall score) with strategies of problem resolution was performed. The results showed $\left(R^{2}=.26\right)$ that the predictors of relationship quality were dialogue $(t=3.99, p<.001)$ and conflict escalation $(t=-3.02, p=.003)$ (Table 3).

Linear regression analysis was also performed for the variable relationship quality (DAS overall score) and five facets of mindfulness (FFMQ). The results showed $\left(R^{2}=.06\right)$ that mindfulness components were not statistically significant predictors of relationship quality (Table 4).

Moreover, a linear regression was performed for the dependent variable of relational quality, considering all variables included in the study. The results $\left(R^{2}=.39\right)$ showed that the predictors of relationship quality were dialogue $(t=4.15, p<.001)$, conflict escalation $(t=-4.16, p<.001)$, and acting with awareness $(t=1.71, p=.089)$. The relationship status, i.e. engagement $(t=3.36, p<.001)$ and marriage $(t=2.59$, $p=.011$ ), was also a predictor. In the examined mod- el, gender, age, and relationship duration were not predictors of relationship quality (Table 5).

\section{DISCUSSION}

The results of the study showed an important role of mindfulness in relationship quality and conflict resolution strategies. Mindfulness was reported to be a predictor of the quality of close relationships. A positive correlation was observed between mindfulness and the overall quality of the relationship, as well as its components (satisfaction, consistency, emotional expression and compliance). It showed that more mindful partners were more satisfied with their close relationships. This confirmed the hypothesis posed in the study that there was a positive relationship between mindfulness of partners and the close relationship quality. It was also consistent with the results of other studies showing the beneficial importance of mindfulness in romantic relationships (Barnes et al., 2007; Burpee \& Langer, 2005; Jones et al., 2011; Kozlowski, 2013).

In the study, statistically significant correlations were noted between mindfulness and its components as well as the sense of relationship quality and its 
Eugenia Mandal, Martyna Lip

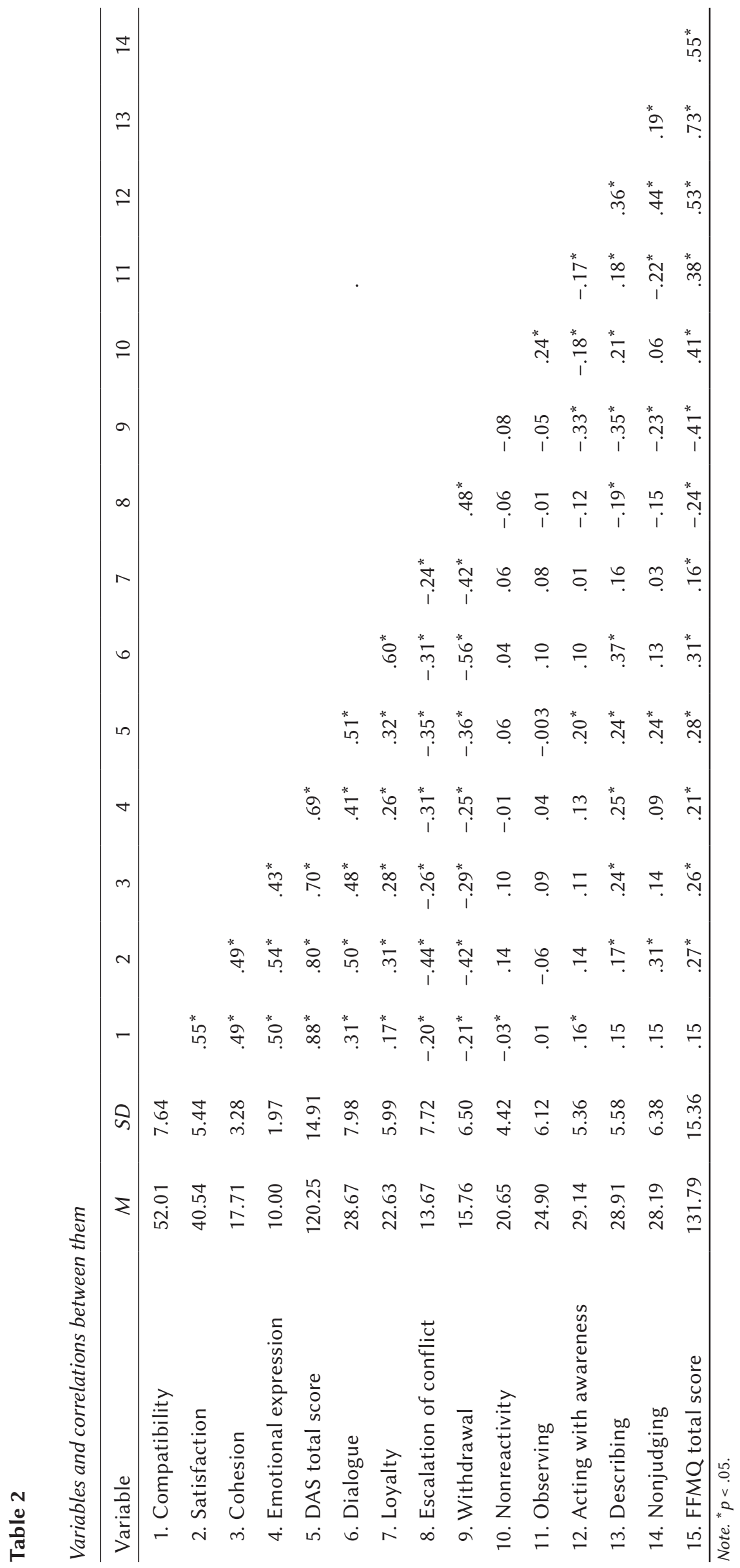


Table 3

Linear regression relationship quality (DAS overall) and patterns of problem resolution

\begin{tabular}{|c|c|c|c|c|}
\hline \multicolumn{5}{|c|}{ Model fit measures } \\
\hline Model & \multicolumn{2}{|c|}{$R^{2}$} & \multicolumn{2}{|c|}{ Adjusted $R^{2}$} \\
\hline 1 & \multicolumn{2}{|c|}{.26} & \multicolumn{2}{|c|}{.24} \\
\hline \multicolumn{5}{|c|}{ Model coefficients - DAS } \\
\hline Predictor & Estimate & $S E$ & $t$ & $p$ \\
\hline Intercept & 102.59 & 7.04 & 14.58 & $<.001$ \\
\hline Dialogue & 0.74 & 0.18 & 3.99 & $<.001$ \\
\hline Loyalty & 0.09 & 0.23 & 0.37 & .711 \\
\hline $\begin{array}{l}\text { Escalation } \\
\text { of conflict }\end{array}$ & -0.48 & 0.16 & -3.02 & .003 \\
\hline Withdrawal & 0.07 & 0.21 & 0.34 & .733 \\
\hline
\end{tabular}

Note. DAS - Dyadic Adjustment Scale.

components (for instance the relationship between nonjudging and satisfaction in a close relationship). It seems reasonable that people who are able to refrain from assessing their partner, his/her features, competences, emotions, intentions, behavioral abilities and who are able to accept the other person as he/she is, with their advantages and disadvantages, feel greater satisfaction from a close relationship.

The study also revealed a relationship between describing and emotional expression. This result showed that partners who were able to recognize and describe their thoughts and emotions of behavior found it easier to show and express their emotions. It facilitated mutual communication and understanding in romantic relationships.

There was also a relationship between nonreactivity and compatibility. This result showed that partners who could refrain from immediate reactions distanced themselves from postponing their reactions, especially in difficult situations, and experienced a greater sense of compatibility with their partner in a romantic relationship.

Acting with awareness also correlated with compliance, which indicates that attentive focus on experiencing the current moments and the situation in the relationship, focusing on the present and not returning to the situation in the past can contribute to satisfaction in the relationship.

The study also confirmed the hypothesis about the relationship between mindfulness and conflict resolution strategies. Mindfulness positively correlated with dialogue, and negatively with escalation of the conflict and the withdrawal strategy. Therefore,
Table 4

Linear regression relationship quality (DAS overall) and five facets of mindfulness (FFMQ)

\begin{tabular}{|c|c|c|c|c|}
\hline \multicolumn{5}{|c|}{ Model fit measures } \\
\hline Model & \multicolumn{2}{|c|}{$R^{2}$} & \multicolumn{2}{|c|}{ Adjusted $R^{2}$} \\
\hline 1 & \multicolumn{2}{|c|}{.06} & \multicolumn{2}{|c|}{.03} \\
\hline \multicolumn{5}{|c|}{ Model coefficients - DAS } \\
\hline Predictor & Estimate & $S E$ & $t$ & $p$ \\
\hline Intercept & 93.76 & 10.69 & 8.77 & $<.001$ \\
\hline Nonreactivity & -0.05 & 0.30 & -0.16 & .874 \\
\hline Observing & 0.11 & 0.22 & 0.53 & .601 \\
\hline $\begin{array}{l}\text { Acting with } \\
\text { awareness }\end{array}$ & 0.24 & 0.29 & 0.85 & .398 \\
\hline Describing & 0.29 & 0.26 & 1.15 & .251 \\
\hline Nonjudging & 0.32 & 0.22 & 1.48 & .140 \\
\hline
\end{tabular}

mindfulness may favor constructive methods of conflict resolution, particularly conversation and mutual listening to each other, and consequently may contribute to greater relational quality. Constructive ways of resolving conflicts (dialogue and loyalty) correlated positively with the relationship quality, while destructive strategies (conflict escalation and withdrawal) were negatively correlated with the relationship quality. These results confirm previous reports (Margolin et al., 1989; Rusbult et al., 1986), which showed the positive influence of constructive patterns and the negative influence of patterns of destructive conflict resolution on the satisfaction of partners in close relationships. Satisfied couples were more likely to use constructive strategies to resolve conflicts, i.e. they preferred dialogue and loyalty as the main ways of dealing with such situations. Destructive strategies (withdrawal, conflict escalation) were used more often by couples with a lower level of relationship satisfaction. Dialogue and loyalty were associated with justifying unpleasant behavior of a partner, as well as faith in his/her good intentions and the hope of changing him/her for the better with time. There was a positive attitude, which makes it possible to deal better with a conflict in a relationship and, consequently, gives greater satisfaction from such a relationship.

The results showed that if the frequency of application of conflict escalation strategies increased, the level of perceived satisfaction decreased too. As in the case of the escalation of the conflict, a negative correlation with satisfaction was noted in the case of withdrawal. The more frequent the use of with- 
Table 5

Predictors of relationship quality. Linear regression results for the explanatory variable relationship quality

\begin{tabular}{lccc}
\hline \multicolumn{3}{l}{ Model fit measures } \\
\hline Model & $R$ & $R^{2}$ & Adjusted $R^{2}$ \\
\hline 1 & .63 & .39 & .29 \\
\hline
\end{tabular}

\begin{tabular}{|c|c|c|c|c|}
\hline \multicolumn{5}{|c|}{ Model coefficients - DAS general results } \\
\hline Predictor & Estimate & $S E$ & $t$ & $p$ \\
\hline Intercept & 89.59 & 17.56 & 5.10 & $<.001$ \\
\hline Dialogue & 0.87 & 0.21 & 4.15 & $<.001$ \\
\hline Loyalty & 0.14 & 0.26 & 0.55 & .586 \\
\hline Escalation of conflict & -0.69 & 0.16 & -4.16 & $<.001$ \\
\hline Withdrawal & 0.27 & 0.23 & 1.20 & .230 \\
\hline \multicolumn{5}{|l|}{ Living with a partner } \\
\hline 2 separate -1 together & -2.30 & 3.16 & -0.73 & .468 \\
\hline 3 partly - 1 together & -0.20 & 4.49 & -0.04 & .964 \\
\hline \multicolumn{5}{|l|}{ Relationship status } \\
\hline 2 engagement -1 couple & 10.97 & 3.26 & 3.36 & .001 \\
\hline 3 marriage -1 couple & 10.40 & 4.02 & 2.59 & .011 \\
\hline \multicolumn{5}{|l|}{ Education } \\
\hline 2 secondary - 1 primary & -0.77 & 9.80 & -0.08 & .938 \\
\hline 3 vocational - 1 primary & 2.90 & 11.36 & 0.26 & .799 \\
\hline 4 higher - 1 primary & -6.59 & 9.99 & -0.66 & .511 \\
\hline \multicolumn{5}{|l|}{ Place of residence } \\
\hline $2100-300,000-1$ up to 100,000 & -0.90 & 2.47 & -0.36 & .716 \\
\hline 3 over $300,000-1$ up to 100,000 & 1.52 & 3.48 & 0.44 & .662 \\
\hline Nonreactivity & 0.19 & 0.28 & 0.71 & .482 \\
\hline Observing & 0.04 & 0.20 & 0.18 & .858 \\
\hline Acting with awareness & 0.46 & 0.27 & 1.71 & .089 \\
\hline Describing & -0.31 & 0.25 & -1.24 & .219 \\
\hline Nonjudging & 0.06 & 0.20 & 0.32 & .749 \\
\hline Gender & -0.91 & 2.42 & -0.38 & .707 \\
\hline Age & -0.13 & 0.27 & -0.51 & .614 \\
\hline Duration of relationship & 0.00 & 0.03 & 0.04 & .967 \\
\hline
\end{tabular}

Note. DAS - Dyadic Adjustment Scale.

drawal as a means of dealing with the conflict, the lower was the level of satisfaction felt. This result was consistent with the research results indicating that low-level relationship satisfaction was associated with more frequent use of combat tactics and the use of negative behaviors (such as punishing the partner, lack of positive messages, not allowing the partner to speak, criticizing him/her, higher reactivity and stimulation), while high-level relationship satisfaction was associated with argument avoidance and the use of constructive tactics (Margolin et al., 1989; Rusbult et al., 1986).

The results of the regression analyses showed that acting with awareness was particularly important 
among the components of mindfulness. In the tested model, mindfulness was a predictor $(p=.089)$ of the relationship quality. However, the analyses showed that constructive strategies of conflict resolution were stronger than acting with awareness predictors of relationship quality: preferring dialogue $(p<.001)$ and avoiding escalation of conflict $(p<.001)$. The way in which partners resolve conflicts significantly influences relational quality. The components of mindfulness were less important for the relationship quality than dialogue in the relationship and avoiding escalation of the conflict. This can be explained by the fact that the skills of constructive problem solving are acquired by people in the course of life and are related to various experiences in conflict situations in life. Constructive conflict resolution skills do not necessarily come from mindfulness alone and from training mindfulness skills. The results of the study confirm the data on the important role of mindfulness in reactions to relationship stress (Barnes et al., 2007).

Furthermore, in the current study, the relationship status (marriage and engagement) was a predictor of relationship quality. Gender, age, education, the place of residence and the duration of the relationship were not predictors of relationship quality. Being engaged or married was a predictor of good-quality relationships. At the same time, the duration of the romantic relationship did not predict its good quality. It can be assumed that relationship quality was largely determined by the social status of the relationship. Moreover, engagement and marriage usually give partners a greater sense of stability, durability, sense of security and certainty than informal relationships.

In the current study, no gender differences were observed as regards mindfulness or relationship quality. This confirms the hypotheses that women and men do not differ significantly in terms of mindfulness, and that both sexes had a similar level of satisfaction with close relationships.

In terms of preferred conflict resolution strategies, it was found that both sexes were most likely to use the dialogue strategy, which is beneficial in resolving problems in close relationships. The noted gender differences were the following: women were more willing to use conflict escalation strategies, while men were more willing to use the loyalty strategy compared to women. This can be explained by a greater tendency of women to argue and over-react emotionally in difficult situations, as well as by greater composure and rationality of men. This confirms the hypotheses that women are more likely to use conflict escalation strategies in close relationships than men. A greater tendency of the surveyed men to use the loyalty strategy than in women may be explained by their greater tendency to rational rather than emotional behavior (Fischer, 2000; Manstead, 1992; Matud, 2004). The result remains consistent with the data showing that women are more likely to exert pressure in close relationships than men (Markman et al., 1994).

In conclusion, the present research showed that mindfulness of partners in close relationships was important for both the quality of the relationship and the preferred conflict resolution strategies. The results of the study may be important for people who want to improve their close relationships.

\section{LIMITATIONS}

However, the study has some limitations. First of all, most participants were relatively young or middleaged, mostly with secondary or higher education. The feelings and behavior of young, middle-aged or elderly people in close relationships may vary. Therefore, further research should be conducted on larger groups of people of different ages.

Secondly, people with a different type and duration of close relationships participated in the study. It can be assumed that the methods of conflict resolution may be different in short-term relationships than in long-term close relationships. Couples with a shorter history may be more likely to use constructive rather than destructive strategies to deal with relationship conflicts compared to couples with a longer history. Similarly, various aspects of the quality of close relationships (e.g. satisfaction with financial distribution) may be different than in relationships with many years of experience. Therefore, further research should be conducted on larger groups of people of different ages with different duration of close relationships.

Third, the subjects had no experience with mindfulness training. In the research on the role of mindfulness, it would also be interesting to compare people who have experience in mindfulness training or various forms of meditation with those who do not.

\section{RefERENCES}

Baer, R. A., Smith, G. T., Hopkins, J., Krietemeyer, J., \& Toney, L. (2006). Using self-report assessment methods to explore facets of mindfulness. Assessment, 13, 27-45. https://doi.org/10.1037/t05514-000

Baer, R., Lykins, E., \& Peters, J. (2012). Mindfulness and self-compassion as predictors of psychological well-being in long-term meditators and matched no meditators. Journal of Positive Psychology, 7, 230-238. https://doi.org/10.1080/17439 760.2012 .674548

Barnes, S., Brown, W. K., Krusemark, E., Cambel, K. W., \& Rogge, R. D. (2007). The role of mindfulness in romantic relationship satisfaction and responses to relationship stress. Journal of Marital and Family 
Therapy, 33, 482-500. https://doi.org/10.1111/j.17520606.2007.00033.x

Bloch, J. H., Farrell, J. E., Hook, J. N., Van Tongeren, D. R., Penberthy, J. K., \& Davis, D. E. (2017). The effectiveness of a meditation course on mindfulness and meaning in life. Spirituality in Clinical Practice, 4, 100-112. https://doi.org/10.1037/ scp0000119

Birditt, K. S., Wan, W. H., Orbuch, T. L., \& Antonucci, T. C. (2017). The development of marital tension: Implications for divorce among married couples. Developmental Psychology, 53, 1995-2006. https://doi.org/10.1037/dev0000379

Bodenmann, G., Charvoz, L., Cina, A., \& Widmer, K. (2001). Prevention of marital distress by enhancing the coping skills of couples: 1-year follow-upstudy. Swiss Journal of Psychology, 60, 3-10. https:// doi.org/10.1024/1421-0185.60.1.3

Brown, K. W., \& Ryan, R. M. (2003). The benefits of being present. Mindfulness and its role in well-being. Journal of Personality and Social Psychology, 84, 822-848. https://doi.org/10.1037/0022-3514.84.4.822

Burpee, L. C., \& Langer, E. J. (2005). Mindfulness and marital satisfaction. Journal of Adult Development, 12, 43-51. https://doi.org/10.1007/s10804-005-1281-6

Carson, J.W., Carson, K. M., Gil, K. M., \& Baucom, D. H. (2004). Mindfulness-based relationship enhancement. Behavior Therapy, 35, 471-494. https://doi. org/10.1016/S0005-7894(04)80028-5

Cieślak, K. (1989). Polska wersja skali G. B. Spaniera służącej do pomiaru jakości związku małżeńskiego (DAS) [Polish version of the G. B. Spanier scale for measuring the quality of marriage (DAS)]. Przeglad Psychologiczny, 32, 1041-1049.

Creswell, J. D., \& Lindsay, E. K. (2014). How does mindfulness training affect health? A mindfulness stress buffering account. Current Directions in Psychological Science, 23, 401-407. https://doi.org/ 10.1177/0963721414547415

Davidson, R. J. (2010). Empirical explorations of mindfulness: Conceptual and methodological conundrums. Emotions, 10, 8-11. https://doi.org/10.1037/ a0018480

Dekeyser, M., Raes, F., Leijssen, M., Leysen, S., \& Dewulf, D. (2008). Mindfulness skills and interpersonal behaviour. Personality and Individual Differences, 44, 1235-1245. https://doi.org/10.1016/j. paid.2007.11.018

Didonna, F. (Ed.). (2009). Clinical handbook of mindfulness. Springer Science + Business Media.

Eagly, A. H., \& Crowley, M. (1986). Gender and helping behavior: a meta-analytic review of the social psychological literature. Psychological Bulletin, 100, 283-308. https://doi.org/10.1037/0033-2909. 100.3.283

Eagly, A. H., \& Koenig, A. M. (2006). Social role theory of sex differences and similarities: Implication for prosocial behavior. In K. Dindia \& D. J. Canary
(Eds.), Sex differences and similarities in communication (pp. 161-177). Lawrence Erlbaum Associates Publishers.

Eagly, A. H., Wood, W., \& Diekman, A. B. (2000). Social role theory of sex differences and similarities: a current appraisal. In T. Eckes \& H. M. Trautner (Eds.), The developmental social psychology of gender (pp. 123-174). Lawrence Erlbaum Associates Publishers.

Eisenberg, N., \& Lennon, R. (1983). Sex differences in empathy and related capacities. Psychological Bulletin, 94, 100-131. https://doi.org/10.1037/00332909.94.1.100

Fischer, A. H. (Ed.). (2000). Gender and emotion: Social psychological perspectives. Cambridge University Press.

Gunaratana, H. (2002). Mindfulness in plain English. Wisdom Publications.

Ilies, I., Egan, H., \& Mantzios, M. (2019). Comparing state anxiety and mindfulness between mindfulness and loving-kindness meditation whilst controlling for the effect of altruism and boredom. Current Issues in Personality Psychology, 7, 109119. https://doi.org/10.5114/cipp.2019.85412

lida, M., \& Shapiro, A. F. (2017). The role of mindfulness in daily relationship process: Examining daily conflicts and relationship mood. Mindfulness, 8, 1559-1568. https://doi.org/10.1007/s12671017-0727-9

Jacobson, N. S., \& Margolin, G. (1979). Marital therapy: Strategies based on social learning and behavior exchange principles. Brunner/Mazel.

Jones, K. C., Welton, S. R., Oliver, T. C., \& Thoburn, J. W. (2011). Mindfulness, spousal attachment, and marital satisfaction: a mediated model. The Family Journal, 19, 357-361. https://doi. org/10.1177/1066480711417234

Kabat-Zinn, J. (1990). Full catastrophe living: Using the wisdom books of your body and mind to face stress, pain, and illness. Delta Books.

Kabat-Zinn, J. (1994) Wherever you go, there you are: Mindfulness meditation in everyday life. Hyperion.

Kabat-Zinn, J. (2003). Mindfulness-based interventions in context: Past, present and future. Clinical Psychology: Science and Practice, 10, 144-156. https://doi.org/10.1093/clipsy.bpg016

Kappen, G., Karremans, J. C., Burk, W. J., \& BuyukcanTetik, A. (2018). On the association between mindfulness and romantic relationship satisfaction: The role of partner acceptance. Mindfulness, 9, 15431556. https://doi.org/10.1007/s12671-018-0902-7

Keng, S., Smoski, M., \& Robins, C. (2011). Effects of mindfulness on psychological health: a review of empirical studies. Clinical Psychology Review, 31, 1041-1056. https://doi.org/10.1016/j.cpr.2011.04.006

Kaźmierczak, M. (2008). Oblicza empatii w relacjach matżeńskich [Faces of empathy in marital relationships]. Wydawnictwo Uniwersytetu Gdańskiego. 
Korner, E., Carlton, K., \& Shaw, D. (1980). Marital conflict: Relations among behaviors, outcomes and distress. Journal of Consulting and Clinical Psychology, 48, 460-468. https://doi.org/10.1037/0022006x.48.4.460

Kozlowski, A. (2013). Mindful mating: Exploring the connection between mindfulness and relationship satisfaction. Sexual and Relationship Therapy, 28, 92-104. https://doi.org/10.1080/14681994.2012.748 889

Kriegelewicz, O. (2003). Kwestionariusz do badania strategii rozwiązywania konfliktów w parze małżeńskiej [Questionnaire to study strategies for conflict resolution in a married couple]. Nowiny Psychologiczne, 4, 15-31.

Langer, E. J. (1989). Mindfulness. Addison-Wesley.

Lazar, S. (2005). Mindfulness research. In C. Gremer, S. Ronald, \& P. Fulton (Eds.), Mindfulness and psychotherapy (pp. 220-240). Guilford Press.

Mandal, E. (2003). Kobiecość i męskość. Popularne opinie a badania naukowe [Femininity and masculinity. Popular opinions and scientific research]. Wydawnictwo Akademickie Żak.

Mandal, E. (2008). Miłość, władza i manipulacja w bliskich zwiqzkach [Love, power and manipulation in close relationships]. PWN.

Manstead, A. S. R. (1992). Gender differences in emotion. In A. Gale \& M. W. Eysenck (Eds.), Handbook of individual differences: Biological perspectives (pp. 355-387). John Wiley \& Sons.

Margolin, G., Burman, B., \& John, R. S. (1989). Home observations of married couples reenacting naturalistic conflicts. Behavioral Assessment, 11, 101-118.

Margolin, G., \& Wampold, B. E. (1981). Sequential analysis of conflict and accord in distressed and nondistressed marital partners. Journal of Consulting and Clinical Psychology, 49, 554-567. https://doi.org/10.1037/0022-006X.49.4.554

Markman, H. J. (1991). Constructive marital conflict is NOT an oxymoron. Behavioral Assessment, 13, 83-96.

Markman, H. J., Floyd, F. J., Stanley, S. M., \& Storaasli, R. D. (1988). Prevention of marital distress: a longitudinal investigation. Journal of Consulting and Clinical Psychology, 56, 210-217. https://doi. org/10.1037/0022-006X.56.2.210

Markman, H. J., Stanley, S. M., \& Blumberg, S. L. (1994). Fighting for your marriage. Jossey, Bass.

Matud, M. P. (2004). Gender differences in stress and coping styles. Personality and Individual Differences, 37, 1401-1415. https://doi.org/10.1016/ j.paid.2004.01.010

Noller, P. (1987). Nonverbal communication in marriage. In D. Perlman \& S. Duck (Eds.), Intimate relationships: Development, dynamics, and deterioration (pp. 149-175). Sage Publications.

Papies, E. K., Pronk, T. M., Keesman, M., \& Barsalou, L. W. (2015). The benefits of simply observing:
Mindful attention modulates the link between motivation and behavior. Journal of Personality and Social Psychology, 108, 148-170. https://doi. org/10.1037/a0038032

Pepping, C. A., Cronin, T., Lyons, A., \& Caldwell, J. G. (2018). The effects of mindfulness on sexual outcomes: The role of emotion regulation. Archives of Sexual Behavior, 47, https://doi.org/10.1007/s10508017-1127-x

Pepping, C. A., \& Duvenage, M. (2016). The origins of individual differences in dispositional mindfulness. Personality and Individual Differences, 93, 130-136. https://doi.org/10.1016/j.paid.2015.05.027

Radoń, S. (2014). Validation of the Polish adaptation of the Five Facet Mindfulness Questionnaire. Annales of Psychology, 17, 737-760.

Rizal, F., Egan, H., Cook, A., Keyte, R., \& Mantzios, M. (2020). Examining the impact of mindfulness and self-compassion on the relationship between mental health and resiliency. Current Issues in Personality Psychology, 8, 279-288. https://doi.org/10.5114/ cipp.2020.100792

Rusbult, C. E., Johnson, D. J., \& Morrow, G. D. (1986). Impact of couple patterns of problem solving on distress and no distress in dating relationships. Journal of Personality and Social Psychology, 50, 744-753. https://doi.org/10.1037/0022-3514.50.4.744

Sagrestano, L. M., Heavey, C. L., \& Christensen, A. (1999). Perceived power and physical violence in marital conflict. Journal of Social Issues, 55, 65-79. https://doi.org/10.1111/0022-4537.00105

Shapiro, S. L., Carlson, L. E., Astin, J. A., \& Freedman, B. (2006). Mechanisms of mindfulness. Clinical Psychology, 62, 373-386. https://doi.org/10.1002/ jclp.20237

Smith, A. (2006). Cognitive empathy and emotional empathy in human behavior and evolution. The Psychological Record, 56, 3-21. https://doi.org/ 10.1007/BF03395534

Spanier, G. B. (1976). Measuring dyadic adjustment: New scales for assessing the quality of marriage and similar dyads. Journal of Marriage and the Family, 38, 15-28. https://doi.org/10.2307/350547

Spanier, G. B., \& Lewis, R. A. (1980). Marital quality: a review of the seventies. Journal of Marriage and the Family, 42, 825-839. https://doi.org/10.2307/ 351827

Treadway, M. T., \& Lazar, S. W. (2009). The neurobiology of mindfulness. In F. Didonna (Ed.), Clinical handbook of mindfulness (pp. 45-57). Springer Science + Business Media.

Wilmot, W. W., \& Hocker, J. L. (2011). Interpersonal conflict. McGraw-Hill. 